\title{
Why Do People Overwork at the Risk of Impairing Mental Health?
}

\section{Sachiko Kuroda ${ }^{1}$ (D) . Isamu Yamamoto ${ }^{2}$}

Published online: 19 July 2018

(c) The Author(s) 2018

\begin{abstract}
This study uses longitudinal data on Japanese workers to investigate the relationship between overwork and mental health. Conventional labor supply theory assumes that people allocate their hours of work and leisure to maximize personal utility. However, people sometimes overwork and underestimate the risks of its negative impact on their physical and/or mental health. We incorporate nonpecuniary factors into the conventional utility function. Empirical analysis reveals a nonlinear relationship between the number of hours worked and job satisfaction. We find that job satisfaction increases when people work more than $55 \mathrm{~h}$ per week. However, we also find that hours worked linearly erode workers' mental health. These findings imply that people who overvalue job satisfaction work excessive hours, consequently damaging their mental health. People may hold incorrect beliefs and underestimate the mental health risks of overwork, which may lead them to work longer hours. Our findings imply that educational and regulatory interventions are needed for both workers and employers to reduce the detrimental impacts on mental health caused by overwork.
\end{abstract}

Keywords Mental health · Job satisfaction · Overwork · Hours worked · Overemployment · Underemployment

This study utilizes micro data of questionnaire information based on the "Survey of Companies and Employees on Human Capital Development and Work-Life Balance" which was conducted by RIETI.

Sachiko Kuroda

s-kuroda@waseda.jp

Isamu Yamamoto

yamamoto@fbc.keio.ac.jp

1 Faculty of Education and Integrated Arts and Sciences, Waseda University, 1-6-1 Nishiwaseda Shinjyuku-ku, Tokyo 169-8050, Japan

2 Faculty of Business and Commerce, Keio University, 2-15-45, Mita, Minato-ku, Tokyo 108-8345, Japan 


\section{Introduction}

Conventional labor supply theory in economic literature assumes that people allocate hours worked and leisure to maximize utility (Killingsworth and Heckman 1986; Pencavel 1986; Blundell and Macurdy 1999). However, many people feel weary or exhausted by too much work or too many hours of work. For example, Galinsky et al. (2005) reported that $44 \%$ of US workers often or very often feel overworked. A report by the Trades Union Congress (2015) stated that the number of UK employees working more than $48 \mathrm{~h}$ per week has increased by $15 \%$ since 2010 and warned that working such excessive hours greatly increases the risk of harming peoples' health. The Japanese government's Ministry of Health, Labour and Welfare (2016) interviewed 11,010 Japanese male regular employees and found that more than $55 \%$ felt either a high or an extremely high degree of fatigue. If, according to standard labor supply theory, people rationally allocate hours of work and leisure to maximize utility, it is difficult to explain why people work to the extent of damaging their health. In this study, overwork is defined as a state in which workers allocate long hours to work, leading to detrimental impacts on their mental health. Through econometric approaches, we examine the mechanism of overwork and how it affects people's mental health.

Past studies have not confirmed a significant correlation between long work hours and mental health. The results by van der Hurst (2003) showed that 27 empirical studies conducted by epidemiologists regarding the relationship between long work hours and health did not reach a consistent conclusion. The inconclusive results may be due to the lack of control for potential confounders. For example, Virtanen et al. $(2011,2012)$ examined longitudinal data of British workers and through follow-up studies found that long work hours and the resulting stress may lead to depression and anxiety symptoms. ${ }^{1}$

However, many previous studies conducted by economists have not necessarily reported a negative relation between long work hours and job satisfaction or happiness. ${ }^{2}$ Clark and Oswald (1996) and Clark (1997) found a negative but weak correlation between work hours and job satisfaction. Pouwels et al. (2008) found that longer working hours significantly reduced the level of happiness in men but not in women. Using panel data of citizens from East Germany and West Germany, Van Praag et al. (2003) found that working hours had a non-significant influence on job satisfaction among West Germans but had a positive relationship for East Germans.

Given the mixed results in the previous literature, this study examines the factors, such as nonpecuniary utility, that influence people to allocate long hours to overwork in order to maximize nonconventional personal utility, which may result in detrimental impacts on their mental health. More specifically, it explores the idea that people maximize personal

\footnotetext{
1 Kuroda and Yamamoto (2016) also reported that even after controlling for detailed individual and job characteristics as well as time-invariant individual heterogeneity, long hours worked are among the principal causes of impairing mental health in Japan.

${ }^{2}$ Previous studies in various fields, including psychology, epidemiology, and economics, have investigated the relationship between work hours and mental wellbeing. For example, extensive psychological literature investigates the association between work hours and mental well-being, including detrimental effects such as work-related burnout, fatigue, and distress (van der Hurst 2003; Caruso 2006). The economic literature has considered the relationship between job satisfaction and hours worked (Clark and Oswald 1996; Clark 1997; Van Praag et al. 2003; Pouwels et al. 2008). The results of these studies are not conclusive; some studies have documented the detrimental effects of working long hours on mental health, whereas others have confirmed that no significant relationship exists between hours worked and well-being.
} 
utility, which comprises not only consumption (=work hours) and leisure but also nonpecuniary rewards from work, such as self-realization, self-affirmation, and the satisfaction derived from feeling needed (Elster 1986; Derks et al. 2009; Thoresen et al. 2003).

We hypothesize that people recognize their mental health deterioration when they work long hours; however, they simultaneously tend to overvalue job satisfaction from nonpecuniary factors that arise with hours worked. People may have nonstandard or incorrect beliefs regarding overwork that may have a negative effect on mental health, and they may overestimate the utility obtained from non-pecuniary factors or underestimate the disutility of working long hours (DellaVigna 2009). The source of these nonstandard beliefs may be overconfidence and/or projection bias (Schaefer et al. 2004; Loewenstein et al. 2003). This hypothesis suggests that workers may choose to overwork and neglect the harmful impact of mental health. The results by Schaefer et al. (2004) indicate that extraversion is significantly related to overconfidence. Thus, we investigated what types of workers are likely to hold nonstandard beliefs and work extreme hours. ${ }^{3}$ We discuss these explanatory mechanisms and test our hypotheses using longitudinal survey data from Japanese white-collar workers and examine the relationships among hours worked, job satisfaction, and mental health.

\section{Theoretical Background and Empirical Specifications}

\subsection{Theoretical Background}

We discuss the nature of utility maximization presented in the model proposed by Rätzel (2012), who incorporates nonpecuniary utility into the standard neoclassical utility function. Rätzel (2012) assumes that work generates both labor disutility and nonpecuniary utility from confirmatory feelings, such as job security, belonging, or social status. Under this assumption, the conventional neoclassical utility function, $V^{n}=U(C, F)$, where $C$ denotes consumption and $F$ denotes leisure, is modified as follows:

$$
\begin{aligned}
\mathrm{V}= & U(C, F)+N(L), \\
& U_{C}>0, U_{F}>0, N_{L}>0, U_{c c}<0, U_{F F}<0, N_{L L}<0 .
\end{aligned}
$$

$N(L)$ denotes nonpecuniary utility of work, and $L$ denotes working hours, defined as the difference between available hours $T$ and leisure $F(L=T-F)$.

This utility function indicates that an additional hour worked generates marginal disutility $\left(U_{L}<0\right)$ and marginal utility $\left(N_{L}>0\right)$. Therefore, utility maximizers supply longer working hours given the market wage and budget constraints since they incur less marginal disutility compared to the case without nonpecuniary utility. Rätzel (2012) used the German Socio-Economic Panel and confirmed an empirical relationship between life satisfaction and working hours, which implies a positive nonpecuniary utility of work in Eq. (1). In addition, he indicated that well-being can be represented as an inverse U-shaped curve

\footnotetext{
3 Another explanation for overwork is that work hours are not genuinely determined by the supply side. Rather, they are negotiated between employers and workers. If employers have bargaining power, they can enforce whatever working hours they deem optimal (Steward and Swaffield 1997). If so, the gap between workers' desired work hours and actual hours worked may lower their utility, with resultant damage to their mental health. We also incorporate this factor into a model, which we explain in the following sections.
} 
Fig. 1 The relationship between hours worked and nonpecuniary utility derived from work

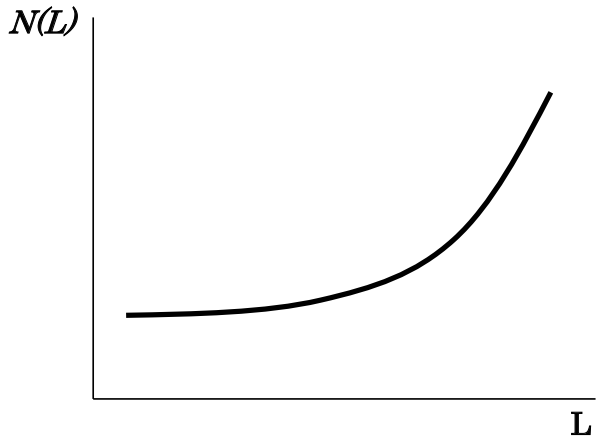

along which life satisfaction rises with shorter working hours but declines as working hours extend. ${ }^{4}$

We extend Rätzel's (2012) utility function in two ways such that long work hours result in greater nonpecuniary utility for workers. Furthermore, some workers may irrationally work extremely long hours despite potential impairment to their mental health.

First, unlike Rätzel (2012), who investigated the well-being of employees with fewer working hours, we focus on workers who hold full-time jobs. The nonpecuniary utility of work $N(L)$ for these workers includes self-realization, self-affirmation, or satisfaction from feeling needed, which is obtained by having responsibility for important or difficult work and the achievement of work that requires great effort. Under such circumstances, nonpecuniary utility rises as employees are assigned to important work or spend long hours accomplishing assigned tasks. In this case, the nonpecuniary utility of work for full-time workers can be illustrated by the half-U-shaped relationship with working hours in Fig. 1.5 With reference to the first term of the Eq. (1), $U(C, F)$, we assume that with a constant consumption level, rising fatigue and declining leisure reduce workers' utility $U(F \mid C)$ as hours worked extend (Fig. 2). To describe the relationship with hours worked, we interpret the decline in mental health as the disutility arising from one additional hour of work. Thus, Fig. 2 illustrates that working longer hours is associated with declining mental health.

Additionally, to allow for the possibility that full-time workers can irrationally choose to overwork despite damaging their mental health, we assume that total utility is a weighted average of standard utility $[U(C, F)]$ and nonpecuniary utility of work $[N(L)]$, as formulated in Eq. (2).

$$
V=\pi U(C, F)+(1-\pi) N(L), \quad 0<\pi<1,
$$

where $(1-\pi)$ denotes a subjective weight to value nonpecuniary utility from work. In the context of our research, $\pi$ denotes a subjective belief about the risks to mental health from working more hours. Since an additional work hour increases both disutility (risk of mental

\footnotetext{
${ }^{4}$ Results also indicate that a reduced level of well-being is associated with fewer working hours, volunteer work and unemployment (Clark and Oswald 1994; Winkelmann and Winkelmann 1998; Blanchflower and Oswald 2004).

${ }^{5}$ Rätzel (2012) indicated an inverse U-shaped relationship between life satisfaction and hours worked. However, he considered all individuals, including the unemployed and part-time workers. Thus, we believe that the U-shaped relationship between nonpecuniary utility and hours worked for full-time workers does not contradict his findings.
} 
Fig. 2 The relationship between hours worked and utility with consumption fixed

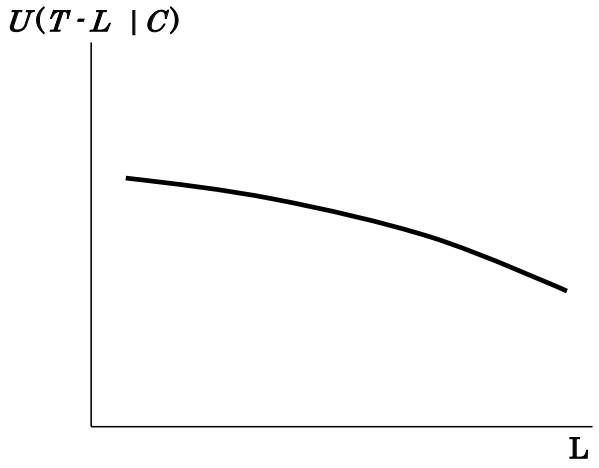

distress) and nonpecuniary utility, total utility depends on how workers evaluate the risks to their mental health.

We believe that workers underestimate their mental health risk $\left(\pi<\pi^{*}\right)$, where $\pi^{*}$ denotes the optimal weight they are assigned to a balanced evaluation of disutility and utility of labor. As long as workers' beliefs are optimal $\left(\pi=\pi^{*}\right)$, long working hours do not erode mental health. However, if workers underestimate the risk $\left(\pi<\pi^{*}\right)$ and overvalue nonpecuniary utility from work, they choose to work excessive hours and potentially endanger their mental health. Hence, this model explains how overworking can threaten mental health.

It is possible that being overconfident or having projection bias may cause people to hold subjective and erroneous beliefs about mental health risks $\left(\pi<\pi^{*}\right)$. DellaVigna (2009) highlighted an overconfidence effect as a typical cause of incorrect beliefs. As confirmed in psychology, this effect is a cognitive bias in which people tend to think in certain ways that can lead to systematic deviations from the norm or rationality in judgment. ${ }^{6}$ Extensive survey and laboratory evidence has established that people are likely to consider their abilities better than average due to unrealistic optimism or miscalibration. At the same time, overconfident individuals hold below-average assessments of negative outcomes, such as health problems. Weinstein $(1980,1982,1987)$ indicated that people systematically underestimate the probability of experiencing health problems due to unrealistic optimism. Sandroni and Squintani (2004) found strong evidence that people often underestimate the risks of attendant activities that they believe are within their control (e.g., driving or financial planning) or that reflect their self-image (e.g., health). According to these studies, it is reasonable to believe that workers who overestimate their abilities and health may suffer the mental health risks associated with overwork and form beliefs characterized by $\pi<\pi^{*}$.

People may hold systematically incorrect beliefs due to projection bias, in which people project the degree to which their future will resemble their current status (DellaVigna 2009). In our case, workers mistakenly assume that their sound mental health will persist and that they are immune to the deleterious effects of working long hours. Given the utility function (2) and findings in psychology and behavioral economics, we assume that some workers willingly overwork and may develop mental disorders.

\footnotetext{
${ }^{6}$ Unlike studies in psychology, several studies in economics have questioned the premise of the overconfidence effect, such as those by Das and van Soest (1999) and Clark and Friesen (2009). In contrast, studies by Hamermesh (1985) and Dominitz (1998) have found the overconfidence effect in many applications.
} 


\subsection{Empirical Specification}

We investigate the empirical implications derived from our model incorporating nonpecuniary utility from work and subjective weightings. We assume that the total utility in Eq. (2) is unobservable, and we assume that nonpecuniary utility from work $[N(L)]$ can be proxied by an index for job satisfaction from being promoted. Nonpecuniary utility increases if full-time workers attain senior positions after extensive effort and hours worked. Thus, we expect that their job satisfaction rises with hours worked. To confirm this relation, we estimate the following equation using panel data:

$$
J S_{i t}=\alpha_{0}+\alpha_{1} L_{i t}+\alpha_{2} L_{i t}^{2}+\boldsymbol{X}_{i t} \boldsymbol{\gamma}+f_{i}+\varepsilon_{i t},
$$

where $J S_{i t}$ denotes an index for the job satisfaction of worker $i$ in year $t, L_{i t}$ denotes the number of hours worked, $\boldsymbol{X}_{i t}$ denotes a vector of control variables, $f_{i}$ denotes a time-invariant individual worker's heterogeneity, and $\varepsilon_{i t}$ denotes an error component. We expect $\alpha_{1}>0$ and $\alpha_{2}>0$ for the coefficients of work hour variables since longer hours worked accelerate rising satisfaction, as the half-U-shaped relation indicates.

We also assume that disutility from work in the standard utility function with constant consumption $U(T-L \mid C)$ can be proxied by an index for workers' mental health. We therefore estimate the equation

$$
M H_{i t}=\beta_{0}+\beta_{1} L_{i t}+\beta_{2} C_{i t}+\mathbf{X}_{i t} \boldsymbol{\delta}+f_{i}+v_{i t},
$$

where $M H_{i t}$ denotes an index for the mental health of worker $i$ in year $t, L_{i t}$ denotes the number of hours worked, $C_{i t}$ denotes consumption, $\boldsymbol{X}_{i t}$ denotes a vector of control variables, $f_{i}$ denotes a time-invariant individual worker's heterogeneity, and $v_{i t}$ denotes an error component. We expect $\beta_{1}<0$ since working long hours generates disutility.

As mentioned in Footnote 3, a gap between workers' desired and actual hours worked may occur if actual work hours are not set optimally and solely by workers but are rather set by factors such as contracts with employers, government regulations, or family matters. Thus, we control for these possibilities by adding deviation terms between desired and actual hours worked in Eqs. (3) and (4) and estimate the following Eqs. (5) and (6):

$$
\begin{aligned}
& J S_{i t}=\alpha_{0}+\alpha_{1} L_{i t}+\alpha_{2} L_{i t}^{2}+\alpha_{3} O E_{i t}+\alpha_{4} U E_{i t}+\boldsymbol{X}_{i t} \boldsymbol{\gamma}+f_{i}+\varepsilon_{i t}, \\
& M H_{i t}=\beta_{0}+\beta_{1} L_{i t}+\beta_{2} C_{i t}+\beta_{3} O E_{i t}+\beta_{4} U E_{i t}+\mathbf{X}_{i t} \boldsymbol{\delta}+f_{i}+v_{i t},
\end{aligned}
$$

where $O E_{i t}$ and $U E_{i t}$ denote overemployment (actual hours worked exceed desired hours) and underemployment (actual hours are fewer than desired).

As indicated by the theoretical model, workers who are likely to hold incorrect beliefs tend to work longer hours. To investigate this theory, we estimate the following equation:

$$
L_{i}=a_{0}+\boldsymbol{P}_{i} \boldsymbol{a}_{1}+\boldsymbol{X}_{\boldsymbol{i}} \boldsymbol{\gamma}+\varepsilon_{i},
$$

where $L_{i}$ denotes the number of hours worked $\left(\log\right.$ term), $\boldsymbol{P}_{i}$ denotes a vector of personality traits, $\boldsymbol{X}_{i}$ denotes a vector of control variables, and $\varepsilon_{i}$ denotes the error term.

Equations (5) and (6) are estimated on the basis of the longitudinal data that enable us to account for the time-invariant individual-specific factors, $f_{i}$, such as personality, habit, and genetic factors. These individual-specific factors are often correlated with other covariates in general and thus produce inconsistent estimates via ordinary least squares. Therefore, in each estimation, we conduct the Hausman test with the null hypothesis that time-invariant individual-specific factors are independent of other covariates. Furthermore, we report the estimation results from either a fixed- or random-effect model, depending on the results of 
the Hausman test. The control for individual-specific heterogeneity based on the longitudinal data is one of the advantages of the methodology for this study.

Conversely, Eq. (7) is estimated on the basis of cross-sectional data since information on personality traits is only available in the latest wave of the longitudinal survey. However, the data used come from the employer-employee matched survey, which allows us to identify each worker's firm. Thus, we can control firm-invariant individual-specific factors, such as long-hour workplace practices, firms' policies for human capital investment, and corporate culture. Therefore, we estimate Eq. (7) both as a group effect model and as a simple linear model.

\section{Method}

\subsection{Participants and Procedure}

We employ the Survey of Companies and Employees on Human Capital Development and Work-Life Balance, an original survey conducted by the research project at the Research Institute of Economy, Trade, and Industry. ${ }^{7}$ Both authors of this study were members of the project and engaged in designing the survey and the content of the questionnaires. The survey is an employer-employee matched panel survey conducted via postal mail with questionnaires for the human resource departments of firms with more than 100 employees and the employees who work at these firms. ${ }^{8}$ The first wave was initiated in February 2012 and repeated at the same time each year from 2013 to 2015, resulting in a total of four waves.

In 2012, each firm was randomly selected from the registration data held by the Ministry of Economy, Trade, and Industry of the Japanese government. The human resource department of each firm was asked to choose at least five white-collar regular employees to participate in the employee survey. Both firms and employees were asked to complete and return questionnaires (by post). For this wave, information became available on 719 of 5677 firms (representing a response rate of 12.7\%) and 4439 matched employees. For the second wave, questionnaires were mailed directly to the firms and employees surveyed in 2012. In the second and fourth waves, newly sampled firms were added and asked to choose at least five white-collar regular employees to be surveyed. ${ }^{9}$ Since information regarding job satisfaction and the deviation between actual and desired hours worked was only available in the third and fourth waves, we only used data collected in those years (2014 and 2015). The total sample size was 4392 workers.

A firm-level survey response rate of $12.7 \%$ is not unusual in Japan considering that this study was not a mandatory official survey but an original survey with many questions that

\footnotetext{
7 The Research Institute of Economy, Trade, and Industry (RIETI) is a policy think tank established in 2001 under the Ministry of Economy, Trade, and Industry of the Japanese government.

${ }^{8}$ Both firms and employees were told in a written document that their responses would be used only for research purposes and were asked to return the questionnaire only if they agreed.

9 To manage attrition, the survey added new samples in the second and fourth waves, a method that is often employed in other longitudinal surveys that are widely used in economics literature, such as PSID of the US, the BHPS of the UK, and the GSOEP of Germany. For the second wave, the survey added information from 176 newly responding firms out of 5008 firms and 505 matched employees. For the fourth wave, the survey added information from 848 new firms out of 10,000 firms and 5433 matched employees. The attrition rates of employee samples were $17.8,60.0$, and $37.4 \%$ for the second, third, and fourth waves, respectively.
} 
was conducted by a policy think tank for academic purposes. For example, a similar firm survey used in Yamamoto and Matsuura (2014) exhibited a 17.4\% response rate. To examine potential selection bias emanating from the low response rate, we explored the representativeness of our sample by comparing key variables, such as average work hours, sex, academic background, marital status, and industry composition, from our employee survey with those of Japanese-government official statistics, specifically the Labour Force Survey (conducted by the Ministry of Internal Affairs and Communications). As indicated in Footnote 11 , our sample largely reflects the general population of Japanese white-collar regular workers.

\subsection{Measurement}

\subsubsection{Job Satisfaction}

The measure of job satisfaction is used widely in longitudinal data, such as the British Household Panel Survey and the German Social-Economic Panel (Clark and Oswald 1996; Clark 1997; Pouwels et al. 2008; Van Praag et al. 2003). Job satisfaction is represented by only one question, "How satisfied are you with job promotion?" as a proxy variable for job satisfaction. Respondents are asked to choose 1 (very unsatisfied), 2 (moderately unsatisfied), 3 (neither satisfied nor dissatisfied), 4 (moderately satisfied), or 5 (very satisfied).

\subsubsection{Mental Health}

To measure employees' mental health, we used the General Health Questionnaire (GHQ). The GHQ includes the GHQ-60, GHQ-28 and GHQ-12 (Goldberg 1972) and has been translated into several languages and used worldwide for decades. We used the abbreviated version, the GHQ-12, which includes 12 items. Respondents were asked to characterize their feelings over the past few weeks from four choices, "not at all," "no more than usual," "rather more than usual," and "much more than usual," in response to the following questions. The psychometric properties of the GHQ-12 have been studied in various populations (Barbosa et al. 2010; Petkovska et al. 2015; Kashyap and Singh 2017).

Question: Have you recently...

1. been able to concentrate on whatever you're doing?

2. lost much sleep over worry?

3. felt that you were playing a useful part in things?

4. felt capable of making decisions about things?

5. felt constantly under strain?

6. felt you couldn't overcome your difficulties?

7. been able to enjoy your normal day-to-day activities?

8. been able to face up to problems?

9. been feeling unhappy or depressed?

10. been losing confidence in yourself?

11. been thinking of yourself as a worthless person?

12. been feeling reasonably happy, all things considered?

To construct an index for mental health status, we used Likert scoring $(0,1,2$, and 3 for "much more than usual," "rather more than usual," "no more than usual," and "not at all," 
respectively). The totals ranged from 0 to 36 , with higher scores implying better mental health. Although GHQ scoring ${ }^{10}$ is generally used in epidemiology, Banks et al. (1980) argued that Likert scoring is more appropriate for parametric analysis. Generally, a lower GHQ score indicates better mental health; however, to compare job satisfaction and the GHQ measures more easily, we inverted the GHQ measure in the present study. Therefore, lower GHQ indicates worse mental health.

\subsection{Other Variables}

\subsubsection{The Number of Hours Worked and the Deviation Term Between Actual and Desired Hours Worked}

The number of hours worked is the actual work hours per week that each respondent reported in the survey. We also included deviation terms between actual and desired hours worked considering that not everyone can choose his or her desired number of hours. To construct the deviation term between actual and desired hours worked, we asked the following questions: "Would you like to increase/decrease number of hours worked given your current wage rate?" and "If so, by how many hours?" For those whose actual hours worked did not equal their desired hours, we converted the gaps into dummy variables for overemployment and underemployment as follows:

$$
\begin{aligned}
\text { Overemployment } & =1 \text { if actual hours worked per week exceed desired work hours per week and } \\
& =0 \text { otherwise. } \\
\text { Underemployment } & =1 \text { if desired work hours per week exceed actual hours worked per week and } \\
& =0 \text { otherwise. }
\end{aligned}
$$

We excluded "do not know" responses from the sample.

\subsubsection{Control Variables}

Control variables included non-labor income, age, tenure, dummy variables for marriage and having children ( 1 if respondents were married and had children and 0 otherwise), and dummy variables for occupation, industry, firm size, and survey year. For the consumption variable of Eq. (6), we included annual income as a proxy. We also included annual income to estimate Eq. (5) as a control variable.

\subsubsection{Personality Traits}

As the variable for personality, we used the "Big Five" personality traits, which comprise five factors: extraversion, neuroticism, openness to experience, conscientiousness, and agreeableness. According to the five-factor model (FFM), these five independent categories are sufficient to describe individual personality differences at the broadest level of abstraction (Costa and McCrae 1992; Goldberg 1990).

\footnotetext{
10 Another common scoring method is the GHQ scoring (0-0-1-1). The responses "not at all" and "no more than usual" are scored 0 , and the responses "rather more than usual" and "much more than usual" are scored 1 . Total scores range from 0 to 12 .
} 
We used the Ten-Item Personality Inventory (TIPI) (Gosling et al. 2003), which was incorporated in the fourth wave of the survey. The TIPI is a 10 -item questionnaire measuring five different facets of personality traits (the Big Five personality dimensions). Responses are provided on a seven-point scale from "strongly disagree" (1) to "strongly agree" (7). We calculated the average of the two bipolar items that constitute each scale (for example, questions 1 and 6 are the two items that capture extraverted personality). Higher scores indicate stronger associations with a certain personality trait.

Question: I see myself as ...

1. extraverted, enthusiastic

2. critical, quarrelsome

3. dependable, self-disciplined

4. anxious, easily upset

5. open to new experiences, complex

6. reserved, quiet

7. sympathetic, warm

8. disorganized, careless

9. calm, emotionally stable

10. conventional, uncreative

\section{Results}

\subsection{Summary Statistics}

Summary statistics for the data used in the following estimation are provided in Tables 1 and $2 .^{11}$

\subsection{Job Satisfaction and Number of Hours Worked}

The estimation results of Eq. (5) investigate the effect of hours worked on job satisfaction. $\mathrm{FE}$ and RE in Table 3 denote the fixed-effects and random-effects models, respectively. We estimate both effects. Only models selected by the Hausman test appear in each column.

Column (1) of Table 3 indicates that the coefficient of work hours is negative and statistically significant at the $1 \%$ level. This finding implies that longer work hours reduce job satisfaction. However, when adding the square term of the number of hours worked in Column (2), the coefficient of the square term is estimated to be positive and statistically significant at the $1 \%$ level, which indicates that the number of hours worked exerts nonlinear effects on job satisfaction. More specifically, the estimated coefficients of hours worked imply that workers' job satisfaction deteriorates with an increase in the number of hours worked but increases beyond a certain number of hours worked.

\footnotetext{
${ }^{11}$ We suggest that our sample largely represents the general population of Japanese white-collar regular workers based on a comparison of key variables listed in Tables 1 and 2 with government official statistics. Average work hours and percentages of sex (male), education (bachelor's degree), marital status, and industry composition (manufacturing sector) in our sample are 44.8, 66.5, 49.4, 64.1, and 23.5, respectively (Tables 1, 2), whereas those of the 2015 Labour Force Survey are 44.7, 57.9, 47.5, 66.4, and 20.9, respectively.
} 
Table 1 Mean, standard deviation, min, and max of continuous variables

\begin{tabular}{llrrl}
\hline & Mean & Std. dev. & Min & Max \\
\hline Work hours & 44.781 & 7.629 & 20 & 88.75 \\
Job satisfaction (promotion) & 2.980 & 0.993 & 1 & 5 \\
GHQ & 14.573 & 5.788 & 0 & 36 \\
Tenure & 11.555 & 9.261 & 0 & 46 \\
Annual income & 460.436 & 207.450 & 200 & 1800 \\
Nonlabor income & 213.046 & 277.021 & 0 & 1600 \\
Age & 41.425 & 10.276 & 19 & 85 \\
Number of children & 1.050 & 1.077 & 0 & 6 \\
Personality big five & & & & \\
$\quad$ Extraversion & 5.065 & 1.515 & 2 & 8 \\
$\quad$ Neuroticism & 4.972 & 1.257 & 2 & 8 \\
Openness to experience & 4.901 & 1.329 & 2 & 8 \\
Conscientiousness & 5.006 & 1.311 & 2 & 8 \\
$\quad$ Agreeableness & 6.015 & 1.101 & 2 & 8 \\
Observations (n) & 4392 & & & \\
\hline
\end{tabular}

aThe number of observations is 3745 for the "Big Five" personality traits

Similar relations between job satisfaction and hours worked appear in Column (3) in Table 3, which includes dummies for hours worked instead of continuous variables. Job satisfaction among respondents working $40-55 \mathrm{~h}$ is significantly lower than among respondents working fewer than $40 \mathrm{~h}$ (indicated by the dummies for work hours). Differences in job satisfaction are small among respondents who work 40-55 h. The results of a $t$ test indicate that we cannot reject the null hypothesis that the difference in the coefficients of hours worked (40-45, 45-50, and 50-55 h) are similar to each other at the $1 \%$ significance. Thus, we assume that job satisfaction is unchanged among respondents who work between 40 and $55 \mathrm{~h}$.

Column (3) in Table 3 indicates that job satisfaction starts to rise from 50-55 h, and the coefficients of the dummies for 55-65 and more than $65 \mathrm{~h}$ worked are not statistically significant. These results indicate that job satisfaction among respondents who work more than $55 \mathrm{~h}$ per week is no less than that among the reference group (less than $40 \mathrm{~h}$ per week) and is more than that among the group that works between 40 and $55 \mathrm{~h}$. It is worth noting that very long work hours (more than $55 \mathrm{~h}$ ) are associated with higher job satisfaction because, as we hypothesized, longer work hours accelerate increased satisfaction.

For the deviation terms between actual hours worked and desired hours worked included in Eq. (5), both coefficients of overemployment and underemployment are positively significant in Column (1) in Table 3, whereas those terms become insignificant in Columns (2) and (3). The results from Columns (2) and (3) indicate that divergence between desired and actual work hours does not seem to affect the degree of job satisfaction.

\subsection{Mental Health and the Number of Hours Worked}

Table 4 presents the estimation results of Eq. (6), which examines the manner in which the number of hours worked affects mental health. The dependent variable is the GHQ-12 
Table 2 Frequency and proportion of categorical variables

\begin{tabular}{|c|c|c|}
\hline Categorical variables & $\mathrm{n}$ & $\%$ \\
\hline \multicolumn{3}{|l|}{ Sex } \\
\hline Male & 2921 & 66.51 \\
\hline Female & 1471 & 33.49 \\
\hline \multicolumn{3}{|l|}{ Education } \\
\hline Bachelor's degree and above & 2173 & 49.48 \\
\hline Other & 2219 & 50.52 \\
\hline \multicolumn{3}{|l|}{ Marital status } \\
\hline Married & 2816 & 64.12 \\
\hline Single & 1576 & 35.88 \\
\hline \multicolumn{3}{|l|}{ Occupation } \\
\hline Professional/skilled & 814 & 18.53 \\
\hline Managerial workers & 1004 & 22.86 \\
\hline Clerical staff & 1880 & 42.81 \\
\hline Clerks & 107 & 2.44 \\
\hline Sales & 508 & 11.57 \\
\hline Other service workers & 79 & 1.80 \\
\hline \multicolumn{3}{|l|}{ Industry } \\
\hline Manufacture sector & 1031 & 23.47 \\
\hline Non manufacture sector & 3361 & 76.53 \\
\hline \multicolumn{3}{|l|}{ Firm size (number of employees) } \\
\hline Less than 29 & 1454 & 33.11 \\
\hline Less than 100 & 1593 & 36.27 \\
\hline Less than 500 & 1165 & 26.53 \\
\hline Less than 1000 & 104 & 2.37 \\
\hline More than 1000 & 76 & 1.73 \\
\hline \multicolumn{3}{|l|}{ Actual and desired work hours } \\
\hline Actual work hours lower than desired work hours & 276 & 6.28 \\
\hline Actual work hours $=$ desired work hours & 1281 & 29.17 \\
\hline Actual work hours higher than desired work hours & 2835 & 64.55 \\
\hline Observations (n) & 4392 & \\
\hline
\end{tabular}

score, which represents respondents' self-assessed mental health (a higher GHQ indicates better mental health). In all estimations, the Hausman test supports the random-effects model over the fixed-effects model.

Column (1) in Table 4 reveals that the coefficient of the number of hours worked is significantly negative at the $5 \%$ level. To determine whether similar results can be observed in Column (2) in Table 3, we incorporate both total hours worked and its squared term. However, in Column (2), both coefficients become insignificant. Unlike job satisfaction, the absence of a nonlinear relationship is evident between hours worked and mental health.

This result is confirmed in Column (3) when we use dummy variables for hours worked. Their coefficients increase in absolute terms as the number of hours worked increases. Compared to workers who work less than $40 \mathrm{~h}$, the mental health scores among workers who work 55-65 h and those who work more than $65 \mathrm{~h}$ per week worsens by 1.6 and 2.4 points, respectively. Job satisfaction among respondents who work more than $55 \mathrm{~h}$ per week is no less than those who work less than $40 \mathrm{~h}$ per week. 
Table 3 Estimation results of the determinants of job satisfaction

\begin{tabular}{|c|c|c|c|}
\hline & (1) & $(2)$ & (3) \\
\hline Total work hours & $\begin{array}{l}-0.0043^{* *} \\
(0.0021)\end{array}$ & $\begin{array}{l}-0.1556^{* * * *} \\
(0.0488)\end{array}$ & \\
\hline Total work hours squared & & $\begin{array}{l}0.0015 * * * \\
(0.0005)\end{array}$ & \\
\hline \multicolumn{4}{|l|}{ Work hours (ref. $=$ less than 40 ) } \\
\hline $40-45 \mathrm{~h}$ & & & $\begin{array}{l}-0.3983 * * \\
(0.1709)\end{array}$ \\
\hline $45-50 \mathrm{~h}$ & & & $\begin{array}{l}-0.5827 * * \\
(0.2269)\end{array}$ \\
\hline $50-55 \mathrm{~h}$ & & & $\begin{array}{l}-0.4915^{* *} \\
(0.2058)\end{array}$ \\
\hline $55-65 \mathrm{~h}$ & & & $\begin{array}{l}-0.3659 \\
(0.2285)\end{array}$ \\
\hline More than $65 \mathrm{~h}$ & & & $\begin{array}{l}0.1085 \\
(0.2662)\end{array}$ \\
\hline \multicolumn{4}{|c|}{ Deviation from preferred working hours } \\
\hline Underemployment & $\begin{array}{l}-0.3056^{* * * *} \\
(0.0661)\end{array}$ & $\begin{array}{l}0.1492 \\
(0.2001)\end{array}$ & $\begin{array}{l}0.1350 \\
(0.2005)\end{array}$ \\
\hline Overemployment & $\begin{array}{l}-0.2312 \text { *** } \\
(0.0337)\end{array}$ & $\begin{array}{l}-0.1624 \\
(0.1213)\end{array}$ & $\begin{array}{l}-0.1829 \\
(0.1237)\end{array}$ \\
\hline The number of observations & 4392 & 4392 & 4392 \\
\hline Model type & $\mathrm{RE}$ & FE & $\mathrm{FE}$ \\
\hline Adj.- $\mathrm{R}^{2}$ & 0.0295 & 0.0004 & 0.0005 \\
\hline
\end{tabular}

Numbers in parentheses are robust standard errors

Estimation also includes non-labor income, age, education, spouse, parenthood, occupation, industry, firm scale, and year dummies

FE and RE stand for fixed- and random-effects models, respectively

$* * *$ and $* *$ indicate statistical significance at the 1 and $5 \%$ levels

These results indicate that the influence of the length of work hours is quite different between job satisfaction and mental health. More specifically, working extremely long hours exerts opposing effects on utility: an increase in nonpecuniary utility (higher job satisfaction) and a decrease in utility (deterioration of mental health).

\subsection{Who Underestimates the Risks of Mental Health?}

Table 5 presents the estimation results of Eq. (7), which investigates the type of worker that is likely to hold incorrect beliefs and, therefore, to work extreme hours. We use the "Big Five" personality traits to investigate this phenomenon. 
Table 4 Estimation results of the determinants of mental health

(1) (2)

Total work hours

$-0.0794 * * *$

$-0.0717$

(0.0121)

$(0.0847)$

Total work hours squared

$-0.0001$

(0.0008)

Work hours (ref. $=$ less than 40)

40-45 h

(0.2319)

45-50 h

$-0.9394 * * *$

(0.2848)

50-55 h

-1.0623 ***

(0.3139)

55-65 h

$-1.6112^{* * * *}$

(0.3933)

More than $65 \mathrm{~h}$

Deviation from preferred working hours

Underemployment

Overemployment

The number of observations

Model type

Adj.-R ${ }^{2}$

Numbers in parentheses are robust standard errors

Estimation also includes non-labor income, annual income, age, education, spouse, parenthood, occupation, industry, firm scale, and year dummies

RE stands for random-effects model

$* * *$ and $* *$ indicate statistical significance at 1 and $5 \%$ levels

Regarding extraversion ${ }^{12}$ as one of the five personality traits, both Columns (1) and (2) in Table 5 indicate that both coefficients are positive at $10-5 \%$ significance levels. Our results indicate that people who exhibit higher extraversion are more likely to work excessive hours and therefore to potentially endanger their mental health.

\section{Discussion}

This study uses longitudinal data from Japanese workers to investigate the relationship between overwork and mental health. Conventional labor supply theory assumes that people allocate consumption and leisure to maximize personal utility. However, people

\footnotetext{
12 Further studies have also examined employees exhibiting extraversion and their behavioral aspects at work (Fox-Hines and Bowersock 1995; Tan and Tiong 1999; Opt and Loffredo 2003; Filbeck et al. 2005).
} 
Table 5 Estimation results of the determinants of hours worked
(1)

(2)

\begin{tabular}{lll}
\hline $\begin{array}{l}\text { Personality big five } \\
\text { Extraversion }\end{array}$ & $0.0032^{*}$ & $0.0054^{* *}$ \\
& $(0.0019)$ & $(0.0021)$ \\
Neuroticism & -0.0008 & -0.0006 \\
& $(0.0022)$ & $(0.0025)$ \\
Openness to experience & 0.0027 & 0.0010 \\
& $(0.0021)$ & $(0.0024)$ \\
Conscientiousness & 0.0018 & 0.0015 \\
& $(0.0021)$ & $(0.0026)$ \\
Agreeableness & 0.0030 & 0.0013 \\
& $(0.0023)$ & $(0.0028)$ \\
The number of observations & 3745 & 3745 \\
Model type & OLS & FE \\
$\mathrm{R}^{2}$ & 0.1414 & 0.3206 \\
\hline
\end{tabular}

Numbers in parentheses are robust standard errors

Dependent variable is the number of hours worked in log term. Explanatory variables also include the $\log$ wage rate, non-labor income, sex, age, education, tenure, spouse, child, occupation, industry, and firm scale dummies

Model type FE indicates fixed-effect (group effect) model controlling for firm-invariant individual-specific factors

** and *indicate statistical significance at the 5 and $10 \%$ levels

sometimes work excessive hours, which affects physical and/or mental health. By using a model that introduces nonpecuniary factors into the conventional utility function, we show that such nonpecuniary factors may motivate people to work long hours even if they recognize the possibility of deleterious consequences for their mental health.

Our main empirical findings reveal a nonlinear relationship between hours worked and job satisfaction (a proxy for nonpecuniary utility). In particular, this study finds that job satisfaction declines as hours worked increase, whereas it begins to rise when hours worked exceed $55 \mathrm{~h}$ a week. To visualize this nonlinearity between job satisfaction and hours worked, in Fig. 3, we simulate the relationship based on estimated coefficients in Column (2) in Table 3.

Figure 3 indicates that job satisfaction does not differ significantly for 40-55 h worked but increases above $55 \mathrm{~h}$ worked. Conversely, as we confirmed in Table 4, longer work hours worsen the mental health of workers (a proxy for disutility from working). Some studies have documented the detrimental effects of working long hours on mental health (van der Hurst 2003; Caruso 2006; Virtanen et al. 2011, 2012), whereas others, particularly in the economics literature, have suggested that no significant relationship exists between hours worked and well-being measured by job satisfaction (Clark and Oswald 1996; Clark 1997; van Praag et al. 2003; Pouwels et al. 2008). Our findings may bridge the gap created by the mixed results of previous studies. The results of this study suggest that mental health and job satisfaction related to long work hours, both broadly categorized as "well-being," do not necessarily have similar results. A worker who insists he is highly satisfied with his job does not necessarily imply that he maintains a 


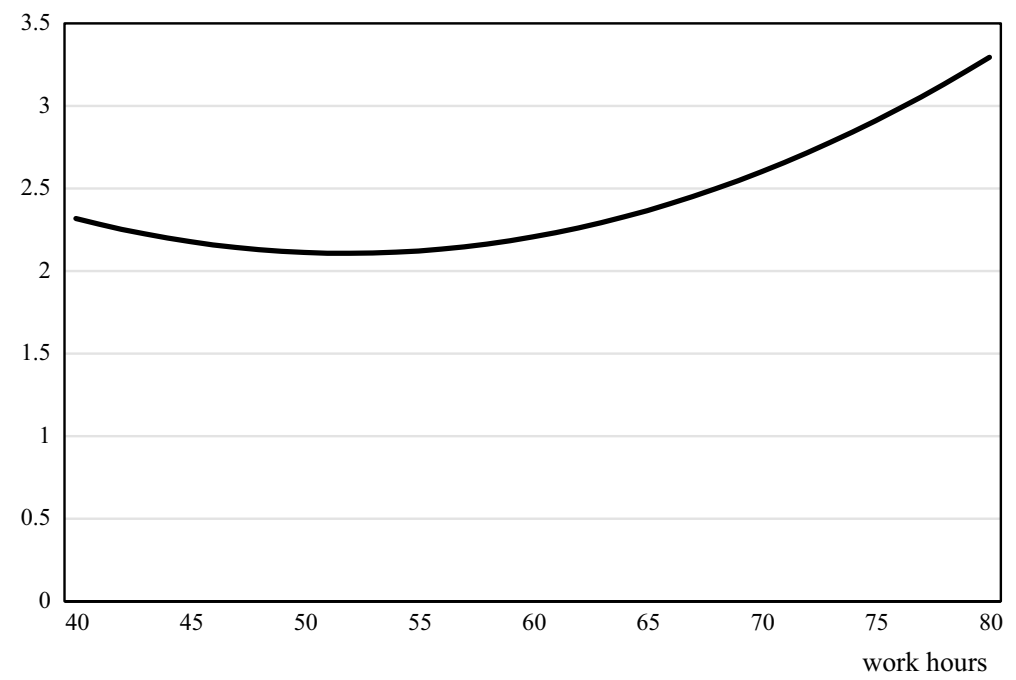

Fig. 3 The estimated relationship between job satisfaction and hours worked. Note: Calculation based on estimation result obtained in Column (2) in Table 3

good mental health condition. More specifically, our results indicate that when workers emphasize their job satisfaction or underestimate the risks of mental health, they may choose to work extreme hours. This may be due to overconfidence (higher extraverted personality traits), over-satisfaction with one's job and overestimation of the positive feelings of job promotion. Workers may choose to work extreme hours to enjoy higher job satisfaction, which could lead to a negative impact on mental health.

The fact that people are likely to hold incorrect beliefs about the risks of mental health and to work longer hours due to overconfidence and projection bias is particularly worth noting. Since these characteristics are prevalent phenomena of human nature, educational and regulatory interventions are needed. Interventions and initiatives may include education for both workers and employers that emphasizes that working extremely long hours may damage mental health and encourages decreased work hours per day, such as regulations addressed in the European Working Time Directive.

Although this study provides an explanation as to why people overwork at the risk of impairing their mental health, several limitations remain for future analysis. First, this study targeted only Japanese workers. Although overworking is not limited to Japanese employees, a relevant term, karoshi (defined in the Oxford English Dictionary as "death caused by overwork or job-related exhaustion"), exists in the Japanese language: ka (excess) + ro (labor) + shi (death). Since similar concepts are widely acknowledged in other countries (Schor 1993; Hamermesh and Slemrod 2008), the results of this study should be considered before generalizing to different populations. ${ }^{13}$

\footnotetext{
13 Regarding empirical findings, various studies report relationships between overwork and mental health in other country contexts or occupations (Appleton et al. 1998, focusing on general practitioners, and Viviers et al. 2008, focusing on ophthalmologists). For example, using US data, Grosh et al. (2006) reported significant associations between work hours and measures of health and well-being, especially for high overtime workers (more than $70 \mathrm{~h}$ per week). Virtanen et al. (2011), using UK longitudinal data, found that working long overtime hours may predispose workers to major depressive episodes.
} 
Second, the sample used in the estimation is limited to workers who were able to answer the longitudinal survey during the different waves of the survey period, which may produce attrition biases. Based on the probit model, this study checked in advance for attrition bias in which respondents who reported impaired mental health in previous years tended to drop out of the survey. The dependent variable in the probit model was a dummy that took the value of 1 for respondents who continued to respond to the survey in the next year and 0 for respondents who dropped out of the survey. The explanatory variables included each respondent's self-reported mental health for the previous year. The estimation results of the probit model reject the possibility that respondents who dropped out of the survey tended to suffer from impaired mental health in the previous year. Although we can confirm that the attrition bias does not seem to be severe, the possibility remains that our results are underestimated because we did not capture responses from workers who took extended sick leave or quit their jobs because of mental illness.

Third, our results indicate that divergence between desired and actual work hours does not affect job satisfaction. Our results are consistent with the findings by Wunder and Heineck (2013), suggesting that there is no relationship between time mismatch and subjective well-being. However, our results are contradictory to other findings (Wooden et al. 2009; Angrave and Charlwood 2015). Angrave and Charlwood (2015) rationalized that the difference in results may emanate from institutional differences, such as working-time regulations among countries. However, their interpretations are speculative, and the issue remains an open question. As mentioned in Wunder and Heineck (2013), the influence of working-time mismatch on well-being has remained largely unexplored (at least in the economics literature). The relationship between time mismatch and subjective well-being as well as the underlying mechanisms to explain the various results obtained in the extant literature remain for future research.

Fourth, the measure of job satisfaction used in this study is limited to "promotion" and not job satisfaction as a whole. Consequently, we checked the relation between the probability of promotion and hours worked using a random-effects probit model in which the dependent variable was 1 if respondents were promoted from the previous year and 0 otherwise. The included covariates were hours worked, individual characteristics, and dummies for occupation, industry, and year. Our results indicated that the greater the number of hours worked, the higher the probability of being promoted. This finding may imply that obtaining a promotion may prompt people to work extremely long hours. However, job satisfaction may arise not only from promotion but also from other factors, such as job characteristics or relationships with colleagues and superiors. To investigate the satisfaction of self-realization and self-affirmation, implementing additional assessments to represent "nonpecuniary utility" will be crucial for future studies. These assessments include other job satisfaction measures (Brayfield and Rothe 1951; Judge et al. 2000; Giacopelli et al. 2013) and questionnaires such as the Hoffman Vocational Self-Realization Scale (HVSRC, Hoffman and Simon 2008) and the Career Adapt-Abilities Scale (Savickas and Porfeli 2012). Determining the psychometric properties of measures and questionnaires used to assess self-realization and self-affirmation continues to be one of our future challenges.

Fifth, the results in Table 5 indicate that more extraverted people are more likely to work excessive hours. This result is consistent with the findings by Schaefer et al. (2004), which indicated that people with higher extraversion are more likely to be overconfident. More specifically, people who exhibit greater extraversion are likely to be overconfident about their health and therefore tend to work excessively without acknowledging that overwork may potentially endanger their mental health. The finding that more extraverted workers are more likely to work long hours is in contrast to the analysis of Uchida et al. (2014), 
who provided evidence that low levels of extraversion are associated with excessive working hours. The different results between the present study and that of Uchida et al. (2014) may be due to the number of observations. ${ }^{14}$ Previous studies investigating the association between extraversion and the number of working hours are scarce, and extended analysis is warranted in the future.

Acknowledgements This study is conducted as a part of the project "Labor Market Analysis Using Matched Employer-Employee Panel Data" undertaken at the Research Institute of Economy, Trade and Industry (RIETI). The authors are grateful for comments and suggestions by Masahisa Fujita, Masayuki Morikawa, Kotaro Tsuru, and seminar participants at RIETI, as well as Daiji Kawaguchi, Hideo Owan, and participants at the Tokyo Labor Economics Workshop. The authors also like to thank two anonymous referees for the constructive comments. This research was supported by Health Labour Sciences Research Grant No. H30-roudou-ippan-004 (Kuroda) and an Grant-in-Aid for Scientific Research (C) from No. 16K03715 (Kuroda) and No. 18K0165 (Yamamoto) the Ministry of Education, Culture, Sports, Science and Technology.

Open Access This article is distributed under the terms of the Creative Commons Attribution 4.0 International License (http://creativecommons.org/licenses/by/4.0/), which permits unrestricted use, distribution, and reproduction in any medium, provided you give appropriate credit to the original author(s) and the source, provide a link to the Creative Commons license, and indicate if changes were made.

\section{References}

Angrave, D., \& Charlwood, A. (2015). What is the relationship between long working hours, over-employment, underemployment and the subjective well-being of workers? Longitudinal evidence from the UK. Human Relations, 68(9), 1491-1515.

Appleton, K., House, A., \& Dowell, A. (1998). A survey of job satisfaction, sources of stress and psychological symptoms among general practitioners in Leeds. British Journal of General Practice, 48, 1059-1063.

Banks, M. H., Clegg, C. W., Jackson, P. R., Kemp, N. J., Stafford, E. M., \& Wall, T. D. (1980). The use of the General Health Questionnaire as an indicator of mental health in occupational studies. Journal of Occupational Psychology, 53, 187-194.

Barbosa, G. A., Oliveira Andrade, E., \& Carneiro, M. B. (2010). Factorial validity and reliability of the General Health Questionnaire (GHQ-12) in the Brazilian physician population. Cad Saude Publica, 26(7), 1439-1445.

Blanchflower, D., \& Oswald, A. (2004). Well-being over time in Britain and the USA. Journal of Public Economics, 88(7-8), 1359-1386.

Blundell, R., \& Macurdy, T. (1999). Labor supply: A review of alternative approaches. In O. C. Ashenfelter \& D. Card (Eds.), Handbook of labor economics, Volume 3, part A, Chapter 27 (pp. 1559-1695). Amsterdam: Elsevier.

Brayfield, A. H., \& Rothe, H. F. (1951). An index of job satisfaction. Journal of Applied Psychology, 35(5), $307-311$.

Caruso, C. (2006). Possible broad impacts of long work hours. Industrial Health, 44(4), 531-536.

Clark, A. E. (1997). Job satisfaction and gender: Why are women so happy at work? Labour Economics, $4(4), 341-372$.

Clark, A. E., \& Oswald, A. J. (1994). Unhappiness and unemployment. Economic Journal, 104(424), 648-659.

Clark, A. E., \& Oswald, A. J. (1996). Satisfaction and comparison income. Journal of Public Economics, 61(3), 359-381.

Clark, J., \& Friesen, L. (2009). Overconfidence in forecasts of own performance: An experimental study. Economic Journal, 119(534), 229-251.

Costa, P. T., Jr., \& McCrae, R. (1992). Normal personality assessment in clinical practice: The NEO personality inventory. Psychological Assessment, 4(1), 5-13.

${ }^{14} n=267$ in Uchida et al. (2014), compared to $n=3745$ in this study. 
Das, M., \& van Soest, A. (1999). A panel data model for subjective information on household income growth. Journal of Economic Behavior \& Organization, 32(1), 137-154.

DellaVigna, S. (2009). Psychology and economics: Evidence from the field. Journal of Economic Literature, 47(2), 315-372.

Derks, B., van Laar, C., \& Ellemers, N. (2009). Working for the self or working for the group: How selfversus group affirmation affects collective behavior in low-status groups. Journal of Personality and Social Psychology, 96(1), 183-202.

Dominitz, J. (1998). Earnings expectations, revisions, and realizations. Review of Economics and Statistics, 35, 17-30.

Elster, J. (1986). Self-realization in work and politics: The marxist conception of the good life. Social Philosophy and Policy, 3(2), 97-126.

Filbeck, G., Hatfield, P., \& Horvath, P. (2005). Risk aversion and personality type. Journal of Behavioral Finance, 6(4), 170-180.

Fox-Hines, R., \& Bowersock, R. B. (1995). ISFJ, ENTP, MBTI: What's it all about? Business and Economic Review, 41(2), 3-7.

Galinsky, E., Bond, J. T., Kim, S., Backon, L., Brownfield, E., \& Sakai, L. (2005). Overwork in America: When the way we work becomes too much. New York: Families and Work Institute.

Giacopelli, N., Kaila, M., Simpson, M., Dalal, R. S., Randolph, K. L., \& Holland, S. J. (2013). Maximizing as a predictor of job satisfaction and performance: A tale of three scales. Judgment and Decision Making, 8(4), 448-469.

Goldberg, D. (1972). The detection of psychiatric illness by questionnaire. Maudsley Monograph, No. 21. Oxford: Oxford University Press.

Goldberg, L. R. (1990). The development of markers for the big-five factor structure. Psychological Assessment, 4(1), 26-42.

Gosling, S. D., Peter, J. R., \& Jr, William B. S. (2003). A very brief measure of the big-five personality domains. Journal of Research in Personality, 37(6), 504-528.

Grosh, J. W., Caruso, C. C., Rosa, R. R., \& Sauter, S. L. (2006). Long hours of work in the U.S.: Associations with demographic and organizational characteristics, psychosocial working conditions, and health. American Journal of Industrial Medicine, 49, 943-952.

Hamermesh, D. S. (1985). Expectations, life expectancy, and economic behavior. Quarterly Journal of Economics, 100(2), 389-408.

Hamermesh, D. S., \& Slemrod, J. B. (2008). The economics of workaholism: We should not have worked on this paper. The B.E. Journal of. Economic Analysis \& Policy, 8(1), 1-28.

Hoffman, E., \& Simon, J. V. (2008). Enhancing employee engagement: A validation study in Venezuela. IHRIM Journal, 12(5), 21-27.

Judge, T. A., Bono, J., \& Locke, E. (2000). Personality and job satisfaction: The mediating role of job characteristics. Journal of Applied Psychology, 85(2), 237-249.

Kashyap, G. C., \& Singh, S. K. (2017). Reliability and validity of general health questionnaire (GHQ-12) for male tannery workers: A study carried out in Kanpur, India. BMC Psychiatry, 17(102), 1-7.

Killingsworth, M. R., \& Heckman, J. J. (1986). Female labor supply: A survey. In O. C. Ashenfelter \& R. Layard (Eds.), Handbook of labor economics (pp. 103-204). Amsterdam: North Holland.

Kuroda, S., \& Yamamoto, I. (2016). Workers' mental health, long work hours, and workplace management: Evidence from workers' longitudinal data in Japan. RIETI Discussion paper, 16-E-017, Research Institute of Economy, Trade and Industry.

Loewenstein, G., O’Donoghue, T., \& Rabin, M. (2003). Projection bias in predicting future utility. Quarterly Journal of Economics, 118(4), 1209-1248.

Ministry of Health, Labour and Welfare. (2016). Karoshi tou nikansuru Jittai Haaku notameno Shakaimen no Chosa Kenkyu Jigyou Houkokusho (Report from the research project to investigate the actual situation of Karoshi; in Japanese). Mizuho Information \& Research Institute.

Opt, S. K., \& Loffredo, D. A. (2003). Communicator image and myers-briggs type indicator extraversionintroversion. The Journal of Psychology, 137(6), 560-568.

Pencavel, J. (1986). Female labor supply: A survey. In O. C. Ashenfelter \& R. Layard (Eds.), Handbook of labor economics (pp. 3-102). Amsterdam: Elsevier.

Petkovska, M. S., Bojadziev, M. I., \& Stefanovska, V. V. (2015). Reliability, validity and factor structure of the 12-Item General Health Questionnaire among general population. Macedonian Journal of Medical Sciences, 3(3), 478-483.

Pouwels, B., Siegers, J., \& Vlasblom, J. D. (2008). Income, working hours, and happiness. Economics Letters, 99(1), 72-74.

Rätzel, S. (2012). Labour supply, life satisfaction, and the (dis)utility of work. Scandinavian Journal of Economics, 114(4), 1160-1181. 
Sandroni, A., \& Squintani, F. (2004). A survey on overconfidence, insurance and self-assessment training programs. New York: Mimeo.

Savickas, M. L., \& Porfeli, E. J. (2012). Career Adapt-Abilities Scale: Construction, reliability, and measurement equivalence across 13 countries. Journal of Vocational Research, 80(3), 661-673.

Schaefer, P., Williams, C., Goodie, A., \& Campbell, K. (2004). Overconfidence and the big five. Journal of Research in Personality, 38(5), 473-480.

Schor, J. (1993). The overworked American: The unexpected decline of leisure. New York: Basic Books.

Steward, M., \& Swaffield, J. (1997). Constraints on the desired hours of work of British men. Economic Journal, 107(441), 520-535.

Tan, V., \& Tiong, T. N. (1999). Personality type and the Singapore manger: Research findings based on the MBTI. Singapore Management Review, 21(1), 15-31.

The Trades Union Congress. (2015). 15 per cent increase in people working more than 48 hours a week risks a return to "Burnout Britain", warns TUC. Septemer 9, 2015, https://www.tuc.org.uk/news/.

Thoresen, C. J., Kaplan, S. A., Barsky, A. P., Warren, C. R., \& de Chermont, K. (2003). The affective underpinnings of job perceptions and attitudes: A meta-analytic review and integration. Psychological Bulletin, 129(6), 914-945.

Uchida, M., Kaneko, M., \& Kawa, S. (2014). Effects of personality on overtime work: A cross-sectional pilot study among Japanese white-collar workers. BMC Research Notes, 7(180), 2-9.

van der Hurst, M. (2003). Long workhours and health. Scandinavian Journal of Work, Environment \& Health, 29(3), 171-188.

van Praag, B. M., Frijters, P., \& Ferrer-i-Carbonell, A. (2003). The anatomy of subjective well-being. Journal of Economic Behavior \& Organization, 51(1), 29-49.

Virtanen, M., Ferrie, J. E., Singh-Manoux, A., Shipley, M. J., Stansfeld, S. A., Marmot, M. G., et al. (2011). Long working hours and symptoms of anxiety and depression: A 5-year follow-up of the Whitehall II study. Psychological Medicine, 41(12), 2485-2494.

Virtanen, M., Stansfeld, S. A., Fuhrer, R., Ferrie, J. E., \& Kivimäki, M. (2012). Overtime work as a predictor of major depressive episode: A 5-year follow-up of the Whitehall II study. PLoS ONE, 7(1), 1-5.

Viviers, S., Lachance, L., Maranda, M.-F., \& Ménard, C. (2008). Burnout, psychological distress, and overwork: The case of Quebec's ophthalmologists. Canadian Journal of Ophthalmology, 43(5), 535-546.

Weinstein, N. D. (1980). Unrealistic optimism about future life events. Journal of Personality and Social Psychology, 39(5), 806-820.

Weinstein, N. D. (1982). Unrealistic optimism about susceptibility to health problems. Journal of Behavioral Medicine, 5(4), 441-460.

Weinstein, N. D. (1987). Unrealistic optimism about susceptibility to health problems: Conclusions from a community-wide sample. Journal of Behavioral Medicine, 10(5), 481-500.

Winkelmann, L., \& Winkelmann, R. (1998). Why are the unemployed so unhappy? Evidence from panel data. Economica, 65(257), 1-15.

Wooden, M., Warren, D., \& Drago, R. (2009). Working time mismatch and subjective well-being. British Journal of Industrial Relations, 47(1), 147-179.

Wunder, C., \& Heineck, G. (2013). Working time preferences, hours mismatch and well-being of couples: Are there spillovers? Labour Economics, 24, 244-252.

Yamamoto, I., \& Matsuura, T. (2014). Effect of work-life balance practices on firm productivity: Evidence from Japanese firm-level panel data, The B.E. Journal of Economic Analysis \& Policy, 14(4), 1677-1708. 